Case Report

\title{
Anesthetic Management of a Patient with Sustained Severe Metabolic Alkalosis and Electrolyte Abnormalities Caused by Ingestion of Baking Soda
}

\author{
Jose Soliz, Jeffrey Lim, and Gang Zheng \\ Department of Anesthesiology and Perioperative Medicine, MD Anderson Cancer Center, Houston, TX 77030, USA \\ Correspondence should be addressed to Jose Soliz; jsoliz@mdanderson.org
}

Received 8 June 2014; Accepted 30 July 2014; Published 10 August 2014

Academic Editor: Kuang I. Cheng

Copyright (C) 2014 Jose Soliz et al. This is an open access article distributed under the Creative Commons Attribution License, which permits unrestricted use, distribution, and reproduction in any medium, provided the original work is properly cited.

\begin{abstract}
The use of alternative medicine is prevalent worldwide. However, its effect on intraoperative anesthetic care is underreported. We report the anesthetic management of a patient who underwent an extensive head and neck cancer surgery and presented with a severe intraoperative metabolic alkalosis from the long term ingestion of baking soda and other herbal remedies.
\end{abstract}

\section{Introduction}

Little is known about the impact of alternative medicine on perioperative anesthetic care. We present a case of a patient who was under the long term management of a naturalistic doctor for a history of colon cancer. His prescribed treatment remedy constituted of a combination of herbs and alkaline fluid. This history was not elicited preoperatively. His intraoperative arterial blood gas test revealed unexpected profound metabolic alkalosis and multiple electrolytes abnormalities. This case presented some unique challenges in intraoperative hemodynamic and electrolyte management.

\section{Case Report}

A 63-year-old $75 \mathrm{~kg}$ male with a history of sinonasal melanoma presented for an endoscopic ethmoidectomy, sphenoidectomy, maxillectomy, palatectomy, and bilateral neck dissection. His past medical history included a 12-year history of colon cancer, which had been managed with a "nature remedy" in Mexico. His remedy included 4Life Transfer Factor Plus, Choice Fifty, Orasal, Boluoke, Grano Derma, Resveratrol Plus, and vitamins C, E, and D. He denied any other medical or surgical issues in the past. His laboratory report 14 days prior to surgery revealed potassium $3.2 \mathrm{mEq} / \mathrm{L}$, chloride $94 \mathrm{mEq} / \mathrm{L}$, and bicarbonate $31 \mathrm{mEq} / \mathrm{L}$. All other electrolyte, renal, and liver function labs were within normal range. On preoperative anesthesia assessment, his vital signs were within normal limits, and his physical exam was normal with the exception of a large mass on the right side of his face.

He was brought to operating room with $2 \mathrm{mg}$ of midazolam premedication. Upon arrival at the operating room he became difficult to arouse. General anesthesia was induced with $150 \mathrm{mg}$ of propofol, $20 \mathrm{mcg}$ of sufentanil, and $70 \mathrm{mg}$ of rocuronium and was maintained with air, oxygen, and 0.6-0.7 MAC of desflurane plus $0.1 \mathrm{mcg} / \mathrm{kg} / \mathrm{hr}$ of sufentanil infusion. After 1.5 hours of surgery, the patient received one liter of plasmalyte with minimal blood loss. A baseline arterial blood gas reported severe metabolic alkalosis and multiple electrolytes derangements (Table 1 at 0919). A blood chemistry test confirmed the accuracy of blood gas report. Therefore, 1 gram of calcium chloride, 2 grams of magnesium sulfate, $40 \mathrm{mEq}$ of potassium chloride in $800 \mathrm{~mL}$ of normal saline (an institutional policy for peripheral IV potassium), and $100 \mathrm{mg}$ of hydrocortisone were given. The ventilator settings were adjusted to target the $\mathrm{ETCO}_{2}$ of $40 \mathrm{mmHg}$. After about 2.5 hours into the surgery, his blood pressure decreased from $110 \mathrm{~s} / 70 \mathrm{~s} \mathrm{mmHg}$ to $80 \mathrm{~s} / 60 \mathrm{~s} \mathrm{mmHg}$. Meantime, he had a total fluid balance of $4,000 \mathrm{~mL}$ of plasmalyte, $700 \mathrm{~mL}$ of blood loss, and $175 \mathrm{~mL}$ of urine output. After several boluses of vasopressin and phenylephrine, a 4-unit/hr vasopressin infusion was added to his treatment. His BP remained low in $80 \mathrm{~s} / 60 \mathrm{smmHg}$, for which he frequently required boluses of phenylephrine and ephedrine. His EKG showed regular 
TABLE 1: Intraoperative laboratory values.

\begin{tabular}{lcccccc}
\hline & \multicolumn{6}{c}{ Time } \\
& 0919 & 0954 & 1115 & 1226 & 1435 & 1738 \\
\hline $\mathrm{pH}$ & 7.65 & 7.53 & 7.48 & 7.49 & 7.51 & 7.44 \\
$\mathrm{CO}_{2}$ & 35 & 44 & 47 & 44 & 41 & 46 \\
$\mathrm{O}_{2}$ & 198 & 193 & 183 & 205 & 202 & 266 \\
$\mathrm{HCO}_{3}$ & 39 & 37 & 35 & 34 & 33 & 31 \\
Base excess & 17 & 13 & 10 & 9 & 9 & 6 \\
Sodium & 123 & 124 & 127 & 126 & 127 & 129 \\
Potassium & 2.6 & 2.5 & 3.3 & 3.4 & 2.9 & 3.2 \\
Glucose & 157 & 208 & 230 & 258 & 271 & 225 \\
Calcium (ionized) & 0.89 & 1.16 & 1.18 & 1.03 & 0.98 & 1.11 \\
Lactate & 1.3 & 1.8 & 1.9 & 2.3 & 3.1 & 3.5 \\
Hematocrit & 42 & 38 & 31 & 26 & 34 & 31 \\
\hline
\end{tabular}

sinus rhythm with rate of low $80 \mathrm{~s} \mathrm{bpm}$. The total anesthetic duration was 12 hours. At the end of surgery, he received a total of $7600 \mathrm{~mL}$ of plasmalyte, $1100 \mathrm{~mL}$ of colloid, and $797 \mathrm{~mL}$ of packed blood cells, with $1000 \mathrm{~mL}$ of estimated blood loss and $595 \mathrm{~mL}$ of urine output. In addition, he also received second dose of 1 gram of calcium at the 7 th hour and $40 \mathrm{mEq}$ potassium at the 9th hour of surgery. Table 1 illustrates his intraoperative arterial blood gas results at different time points. He was extubated at the end of surgery in the operating room.

Postoperatively, he developed hallucinations described as "constantly dreaming and difficulty to close eyes." The hallucination disappeared on postoperative day 3 without intervention. His $\mathrm{K}, \mathrm{Na}$, and $\mathrm{CL}$ remained low until postoperative day 6 . His postoperative EKG showed a normal sinus rhythm with a rate of $70 \mathrm{~s} \mathrm{bpm}$. No other issues were identified in his postoperative course. The patient was discharged to home on postoperative day 7.

On postoperative followup, we learned that, for the past 12 years, the patient used herbal medications and also drank an "alkaline liquid": a mixture of 1 liter of $\mathrm{pH}$ 7.8-8 water, typically with bottled water, key lime juice, and a quarter of tablespoon baking soda. The endpoint of the remedy was to achieve urine $\mathrm{pH}$ of $7.58-8$. He stopped all the herbs 5 days prior to surgery per his doctor's advice but kept his "alkaline liquid" until the night before surgery. He never experienced muscular cramping, weakness, or alter mental status in the past.

\section{Discussion}

Baking soda (sodium bicarbonate) has been widely used by people for reasons ranging from increasing excise tolerance to treating acid reflux disease and other medical conditions. Severe cardiac dysrhythmia and death after ingestion of sodium bicarbonate have been reported [1-4]. Ingestion of baking soda results in multiple issues including metabolic and electrolytes derangement. Details on pathophysiological influences of metabolic alkalosis and electrolytes abnormalities are beyond the scope of a case report.

Generally, treating severe metabolic and electrolyte abnormalities during anesthesia is based on patient's baseline condition and clinical symptoms. In our case, the lack of knowledge of etiology and baseline values led to difficulty in determining the endpoint of electrolyte correction. Our goal for this case was to partially restore potassium to a range of $3-3.5 \mathrm{mEq} / \mathrm{L}$ in light of his previous potassium $3.2 \mathrm{mEq} / \mathrm{L}$ to minimize the risk of intraoperative cardiac dysrhythmia. Without knowing his baseline sodium value we decided to use plasmalyte rather than hypertonic saline to avoid the risk of acute sodium overcorrection from his baseline level. This case presented a couple of unique issues. First, the patient developed refractory hypotension despite fluid replacement with the volume that seemed adequate in other similar cases. This might reflect the combined effects of hypovolemia and direct vasodilation from bicarbonate. Kaplan et al. found in their study that bicarbonate is a direct peripheral vasodilator. Under general anesthesia with halothane it caused profound hypotension in health volunteers [5]. Another study showed that even mild metabolic alkalosis induced by bicarbonate resulted in symptomatic hypotension during renal dialysis and required a larger volume infusion than in non-alkalotic patients [6]. Attenuated response to vasopressors was also observed in this case. Despite multivasopressor therapy in addition to fluid replacement, we were not able to achieve sustained blood pressure close to his baseline level. This might have reflected that, under a state of severe alkalosis, the response to vasoactive agents is blunted. Indeed, combined effects of left shift hemoglobin dissociation curve with tissue hypoxia caused by alkalosis, a low perfusion status, and multielectrolyte derangement had put the patient in a high risk of an ischemic event.

Secondly, we observed that the patient presented with a decreased response to stimuli. As described above, with a low anesthetic level, without extra adjustment of anesthetics the patient did not show HR and BP changes in response to multiple skin incisions and head repositions. We suspect that the decrease in anesthetic demand was secondary to a decrease in central nervous system (CNS) response to stimuli secondary to the CSF alkalosis. Sustained metabolic alkalosis with significant multiple electrolyte derangements under general anesthesia is a rare clinical scenario. Little is known about the potential complications and drug pharmacodynamics and pharmacokinetics under this situation.

It is a very common and misleading opinion that alternative medicines are benign and safe, as these remedies have been used worldwide. Lack of regulation and standardization of alternative medicine has made clinical evaluation of patients and their remedies challenging. More importantly, not knowing the impacts of alternative medicine to perioperative patient care will significantly undermine the perioperative risk stratification. Hence, developing an interview protocol and actively seeking history of alternative remedies rather than "patient to tell" during preoperative interview should be as important as the retrieval of any other medical and surgical information.

\section{Conflict of Interests}

The authors declare there is no conflict of interests regarding the publication of this case report. 


\section{References}

[1] L. J. Fitzgibbons and E. R. Snoey, "Severe metabolic alkalosis due to baking soda ingestion: case reports of two patients with unsuspected antacid overdose," Journal of Emergency Medicine, vol. 17, no. 1, pp. 57-61, 1999.

[2] M. H. Nichols, S. Wason, J. G. Del Rey, and M. Benfield, "Baking soda: a potentially fatal home remedy," Pediatric Emergency Care, vol. 11, no. 2, pp. 109-111, 1995.

[3] M. Price, P. Moss, and S. Rance, "Effects of sodium bicarbonate ingestion on prolonged intermittent exercise," Medicine and Science in Sports and Exercise, vol. 35, no. 8, pp. 1303-1308, 2003.

[4] I. B. Gawarammana, J. Coburn, S. Greene, P. I. Dargan, and A. L. Jones, "Severe hypokalaemic metabolic alkalosis following ingestion of gaviscon," Clinical Toxicology, vol. 45, no. 2, pp. 176178, 2007.

[5] J. A. Kaplan, G. L. Bush, J. H. Lecky, A. J. Ominsky, and H. Wollman, "Sodium bicarbonate and systemic hemodynamics in volunteers anesthetized with halothane," Anesthesiology, vol. 42, no. 5, pp. 550-558, 1975.

[6] L. Gabutti, N. Ferrari, G. Giudici, G. Mombelli, and C. Marone, "Unexpected haemodynamic instability associated with standard bicarbonate haemodialysis," Nephrology Dialysis Transplantation, vol. 18, no. 11, pp. 2369-2376, 2003. 


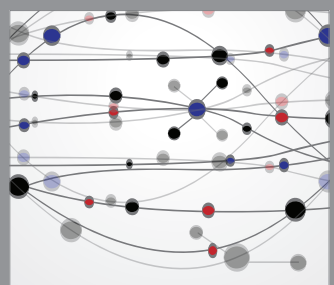

The Scientific World Journal
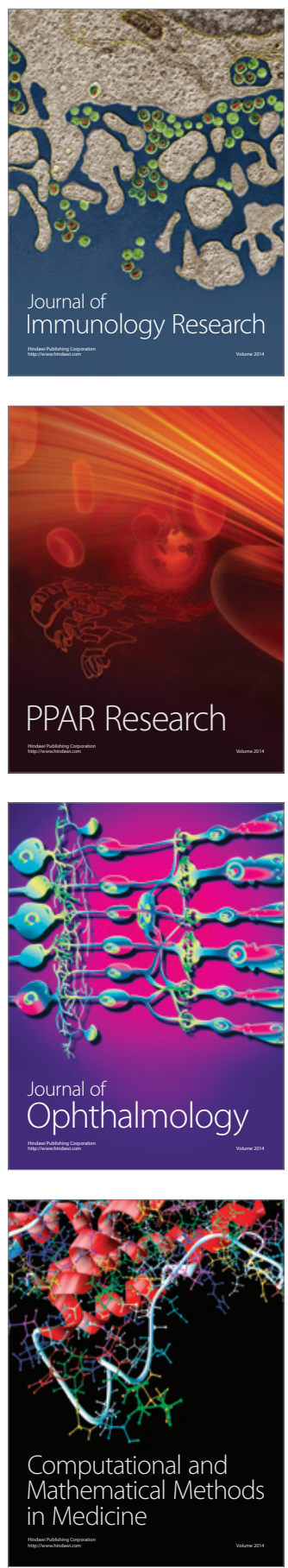

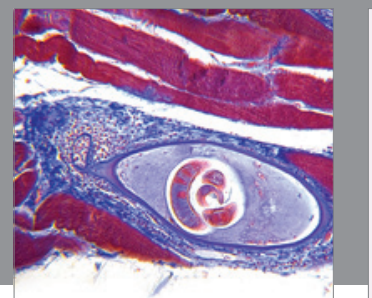

Gastroenterology

Research and Practice
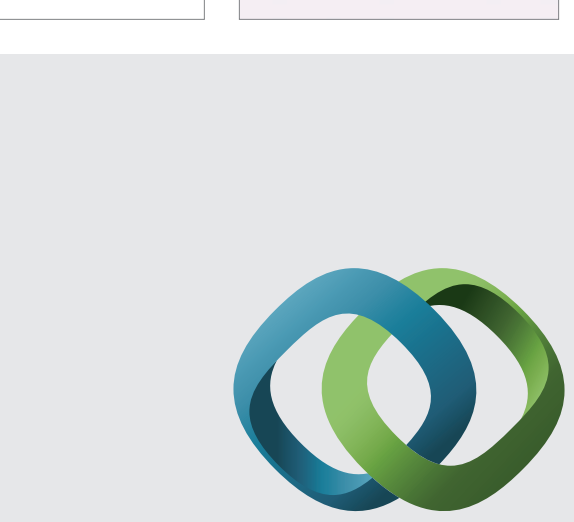

\section{Hindawi}

Submit your manuscripts at

http://www.hindawi.com
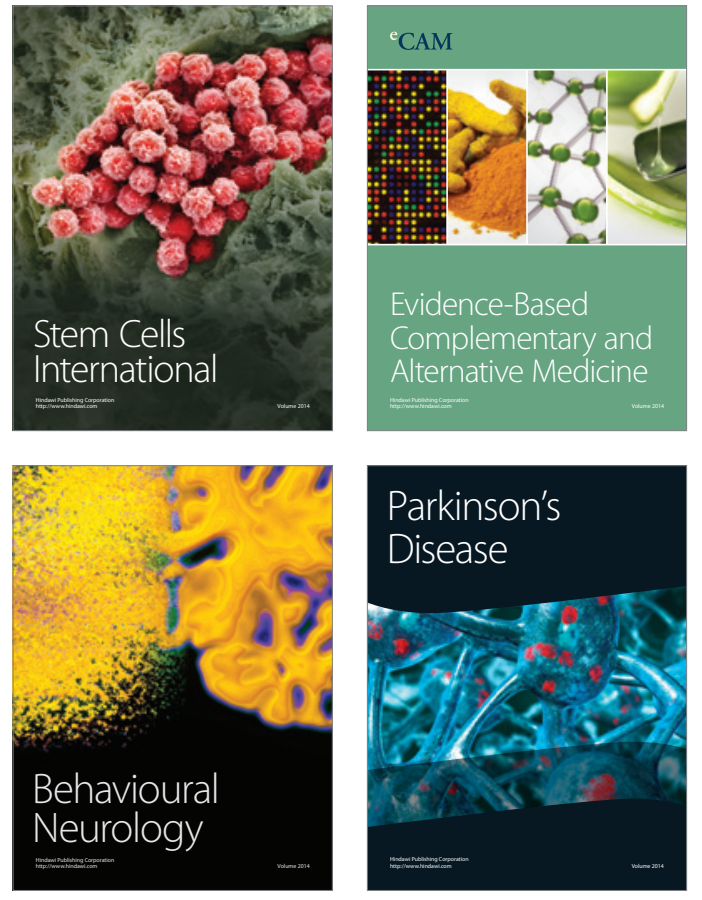
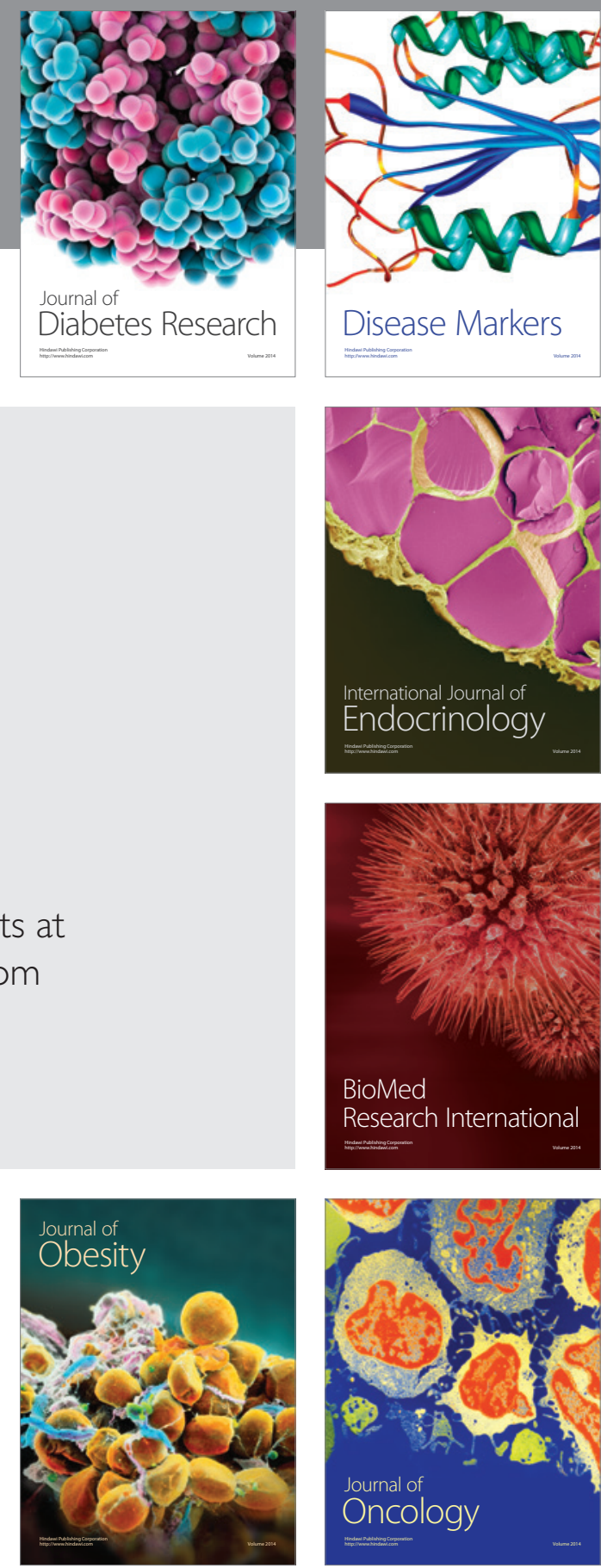

Disease Markers
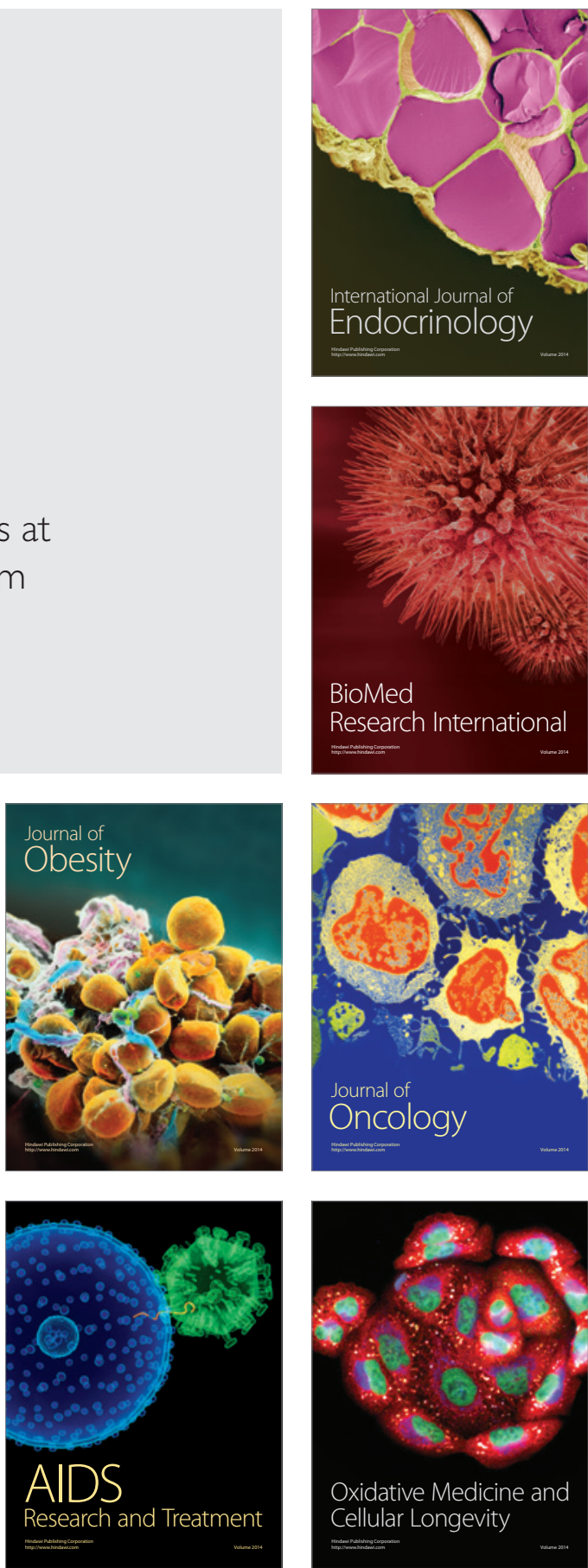